\title{
The effect of L-carnitine therapy on anaemia therapy in paediatric patients on regular haemodialysis
}

\author{
Ghada M. El-Mashad', Mahmoud A. El-Hawy' ${ }^{1}$, Hebatallah M. NaserBahbah', Hanan M. Bedair², \\ Marwa I. Habib ${ }^{3}$ \\ ${ }^{1}$ Paediatric Department, Faculty of Medicine, Menoufia University, Egypt \\ ${ }^{2}$ Clinical Pathology Department, National Liver Institute, Menoufia University, Egypt \\ ${ }^{3}$ Lecturer in clinical pathology, National Liver Institute, Menoufia University, Egypt
}

\section{ABSTRACT}

Introduction: Renal anaemia is a common complication of haemodialysis patients. Hyporesponsiveness to erythropoietin (EPO) has been known as an important factor in poor recombinant human erythropoietin efficacy in the treatment of renal anaemia. Moreover, an increased erythropoiesis resistance index (ERI) may be associated with inflammation and lead to an increased mortality.

The aim of the study to study the effect of L-carnitine (LC) therapy on anaemia and erythropoietin therapy in paediatric patients on regular haemodialysis.

Material and methods: This prospective study was conducted on $30 \mathrm{CKD}$ paediatric patients on regular haemodialysis attending the haemodialysis unit in Menoufia University. They were classified into 2 groups: 15 CKD patients receiving oral L-carnitine (LC) in a dose of $100 \mathrm{mg} / \mathrm{kg}$ per day in 3 divided doses - maximum $3 \mathrm{~g}$ per day and erythropoietin therapy in a dose of 100-300 IU/kg 3 times per week, considered as group I, and $15 \mathrm{CKD}$ patients receiving erythropoietin therapy only (group II). Patients were subjected to history taking, clinical examination, and laboratory investigations including $\mathrm{CBC}$, pre- and post- dialysis serum urea. Creatinine, iron profile, $\mathrm{Ca}$, phosphorus, intact parathormone, erythropoiesis-stimulating agent dose (ESA), and erythropoietin-resistance index (ERI) were calculated at the baseline and then on follow-up after 6 months.

Results: There was a statistically significant increase in $\mathrm{Hb}$ level in patients receiving both L-carnitine and erythropoietin therapy (group I) when compared to patients receiving erythropoietin only (group II) after 6 months. Moreover, there was a significant decrease in the mean erythropoietin-stimulating agent (ESA) dose and erythropoietin-resistance index (ERI) in group I with mean \pm SD of $95.12 \mathrm{IU} / \mathrm{kg} \pm 10.99 \mathrm{IU} / \mathrm{kg}$, $229.59 \pm 21.95 \mathrm{IU} / \mathrm{kg} / \mathrm{g}$ when compared to group II at $149.11 \pm 43.98 \mathrm{IU} / \mathrm{kg}, 360.15 \pm 71.105 \mathrm{IU} / \mathrm{kg} / \mathrm{g}$ ( $p$-value $0.00)$, respectively.

Conclusions: L-carnitine may be used as an adjuvant therapy in paediatric haemodialysis patients to decrease the requirement of erythropoietin-stimulating agents (ESA) dosage and erythropoietin-resistance index (ERI) while maintaining adequate levels of serum haemoglobin.

KEY WORDS:

anaemia, haemodialysis, L-carnitine, paediatric, erythropoietin.

\section{ADDRESS FOR CORRESPONDENCE:}

Mahmoud A. El-Hawy, Paediatric Department, Faculty of Medicine, Menoufia University, Egypt,

e-mail: mahmodelhawy18@yahoo.com 


\section{INTRODUCTION}

Patients with chronic kidney disease (CKD) have a relative erythropoietin (EPO) deficiency. This is considered as the main cause of anaemia in these patients. The severe form of CKD anaemia decreases quality of life and increases the risk of cardiovascular diseases such as left ventricular hypertrophy ( $\mathrm{LVH})$, depressed neurocognitive ability, reduced exercise capacity, progression of cardiovascular risk factors, and mortality in dialysis patients. So, the implementation of prevention and control measures is recommended [1-3].

Erythropoiesis-stimulating agents (ESAs) are generally used to control anaemia and reduce the need for blood transfusions in patients with CKD $[1,4]$. Although ESAs are effective for reversing the anaemic status, the aetiology of anaemia is multifactorial due to other competing factors. The response capacity of these patients is variable [5-7]. The most common cause of erythropoietin resistance is reduced iron availability, including absolute and functional iron deficiency [8]. Hepcidin, a 25-amino-acid peptide predominantly produced by the liver, decreases the release of iron from storage tissues and causes a reduction in iron absorption from the gut. Therefore, hepcidin is involved in the pathogenesis of erythropoietin resistance [9]. Inflammation increases hepcidin production, limiting the availability of iron for erythropoiesis and thus providing a direct link between inflammation and erythropoietin resistance. The reduction of inflammation is a reasonable approach for treating erythropoietin resistance [10].

Carnitine is a hydrophilic amino acid that acts as a cofactor of long fatty-acid metabolism. It has an indirect role in glucose metabolism. This small molecule (162 D) is freely filtered by the glomerular membrane and reabsorbed by the proximal tubule via organic cation carnitine transporter 2 receptors, with a renal clearance of about $1-3 \mathrm{ml} / \mathrm{min}[11]$.

Carnitine participates in the de-acylation and re-acylation processes that remodel erythrocyte phospholipid membranes, stimulate erythropoiesis at high concentrations (> $200 \mu \mathrm{mol} / \mathrm{l})$, increase the survival time of erythrocytes, and reduce oxidative stress via heme oxygenase 1 and inflammation [12].

Plasma carnitine levels decrease by about $80 \%$ by the end of a dialysis session. This depletion is restored after the session, from endogenous synthesis, cellular storage, and food intake. However, many factors affect the endogenous synthesis including dialysis of cofactors of carnitine synthesis, such as vitamin $B_{6}$, niacin, vitamin $C$, lysine, and methionine, and protein malnutrition. Consequently, carnitine depletion develops immediately after the start of haemodialysis and increases with duration of dialysis. Furthermore, free carnitine is dialyzed at a higher rate than acylcarnitine. This tends to invert the plasma acyl/free carnitine level, which can exceed 0.4 [11].
Nutrition influences anaemia correction in haemodialysis by several pathways, including folic acid, vitamin B, vitamin $\mathrm{C}$, carnitine, iron deficiencies, and a decrease in antioxidative capacity that produces a proinflammatory effect [13].

\section{AIM OF THE STUDY}

The aim of this work was to study the effect of L-carnitine (LC) supplementation with erythropoietin therapy in the treatment of renal anaemia in paediatric patients on regular haemodialysis.

\section{MATERIAL AND METHODS}

The study was carried out in the paediatric haemodialysis unit in the paediatric nephrology unit in Menoufia University and Clinical Pathology Department, National Liver Institute, Menoufia University during the period from March 2019 to September 2019. The study included 30 paediatric patients attending the paediatric haemodialysis unit with chronic renal failure on regular haemodialysis 3 times weekly for at least 3 months after obtaining written consent from their parents. The local ethics committee of Menoufia University approved the study protocol.

\section{MATERIAL}

The study included 30 paediatric Egyptian patients aged less than 18 years with chronic renal failure on regular haemodialysis for at least 3 months. The patients were divided into 2 groups: Group I included 15 patients receiving oral L-carnitine (LC) in a dose of $100 \mathrm{mg} / \mathrm{kg}$ per day in 3 divided doses - maximum $3 \mathrm{~g}$ per day, as described by Warady et al. [14], and erythropoietin therapy in a dose of 100-300 IU/kg 3 times per week. Group II received only erythropoietin therapy in a dose of 100-300 IU/kg 3 times per week, as described by Gagnadoux et al. [15]. The patients received about 5-10 blood transfusions prior to the study

Exclusion criteria: Patients with autoimmune disease, chronic haemolytic anaemia, or malignancy were excluded from the study.

\section{ALL PATIENTS WERE SUBJECTED TO THE FOLLOWING:}

Full patient history taking, including history of the original disease.

Clinical examination: full clinical examination including the following:

Vital signs: blood pressure was recorded and compared to the median ( $50^{\text {th }}$ percentile) for age and sex using Egyptian standard growth charts. 
Anthropometric measures: height and weight of the patients were recorded; both were compared to the median $\left(50^{\text {th }}\right.$ percentile) for age and sex using Egyptian standard growth charts.

\section{METHODS}

By using sterile vein-puncture, $8 \mathrm{ml}$ of venous blood was withdrawn from each patient and divided into 2 tubes. First, $4 \mathrm{ml}$ blood was transferred into 2 EDTA tubes. The first one was used for CBC measurement performed on a Sysmex XT-1800i automated haematology analyser (Sysmex, Japan). The second EDTA tube was centrifuged for $10 \mathrm{~min}$ at $4000 \mathrm{rpm}$ and stored at $-80^{\circ} \mathrm{C}$. Another $4 \mathrm{~mL}$ of blood was transferred into a plain tube and allowed to clot at $37^{\circ} \mathrm{C}$ and centrifuged for $10 \mathrm{~min}$ at $4000 \mathrm{rpm}$. Serum was used for determination of kidney function tests (urea and creatinine) using a Cobas e501 autoanalyser (Roche-Germany), iron profile (iron, total iron binding capacity “TIBC”, Transferrin saturation, Ferritin) on a modular Cobas 6000 c501 system (Roche-Diagnostics, Germany), and calcium (Ca) and phosphorus were done by AU480 chemistry analyser (Beckman Coulter Diagnostics).

\section{Intact parathormone measurement}

Determination of serum iPTH was done by enzyme-linked immunosorbent assay (ELISA) using a $\mathrm{Hu}$ man Parathyroid Hormone (PTH) ELISA Kit (INNOVA BIOTECH CO., Ltd., China). This ELISA kit uses a sandwich ELISA method. The Microelisa strip plate provided in the kit is pre-coated with an antibody specific to PTH. Standards or samples are added to the appropriate wells and combined to the specific antibody. Then a Horseradish Peroxidase (HRP)-conjugated antibody specific for PTH is added to each well and then incubated followed by a washing step to remove free components. The TMB substrate solution is then added to each well. Only wells that contain PTH and HRP-conjugated PTH antibody will appear blue in colour and turn yellow after the addition of the stop solution. The OD value is proportional to the concentration of PTH and is measured spectrophotometrically at a wavelength of $450 \mathrm{~nm}$. We calculated the concentration of PTH in the samples by comparing the OD of the samples to the standard curve. Assay range was $3.3-200 \mathrm{pg} / \mathrm{ml}$.

\section{Adequacy of dialysis}

The urea reduction ratio is a function of the clearance of urea from the blood by the dialyzer, the length of the individual dialysis treatment, and the volume of distribution of urea in a particular patient. Therefore, the urea reduction ratio is a quantitative measurement of an individual patient's urea clearance during a single haemodialysis treat- ment and can be used as a proxy for the adequacy of solute clearance during a treatment $[16,17]$.

The urea reduction ratio as a measure of the adequacy of dialysis is calculated with the formula $100 \times(1-[\mathrm{Ct} /$ $\mathrm{Co}]$ ), in which $\mathrm{Ct}$ is the blood urea nitrogen measured 5 minutes after the end of dialysis and Co is the pre-dialysis blood urea nitrogen [18].

We also analysed serum levels of haemoglobin and erythrocytes, erythropoiesis-stimulating agent dose (ESA), and erythropoietin-resistance index (ERI) in $\mathrm{U} / \mathrm{Kg} / \mathrm{g}$, which were calculated as the mean weekly adjusted dose of erythropoietin in units per $\mathrm{kg}$ body weight divided by the average haemoglobin in grams [19].

Measurements were made at the baseline and then on follow-up after 6 months.

\section{Statistical analysis of data}

The data were coded, entered, and processed on a computer using SPSS (version 24). The results were represented in tabular and diagrammatic forms and then interpreted. Mean, standard deviation, range, frequency, and percentage were used as descriptive statistics. The chi-square test and $\chi^{2}$ test were used for the association variables for categorical data. Student's $t$-test was used to assess the statistical significance of the difference between 2 population means in a study involving independent samples. The paired samples $t$-test was used to assess the statistical significance of the difference between 2 population means in a study involving paired samples. The $p$ value was considered significant as follows: $p>0.05$ - non-significant, $p \leq 0.05$ - significant.

\section{RESULTS}

There were no statistically significant differences between studied groups regarding age, sex, height, weight, or BMI index centiles. There were no statistically significant differences between studied groups regarding differences in systolic or diastolic blood pressure centiles, implying good selection of cases (Table 1).

Table 2 showed no statistically significant difference regarding pre-dialysis serum urea and creatinine, post-dialysis urea and creatinine, urea reduction ratio (URR), calcium (Ca), phosphorus (P), and parathyroid hormone (PTH) between the studied groups. There were no statistically significant differences regarding iron profile between the studied groups.

The results shown in Table 3 reveal no statistically significant difference between the studied groups regarding haemoglobin level, mean erythropoietin-stimulating agent (ESA) dose, and mean erythropoietin-resistance index (ERI) before the start of L-carnitine supplementation. Six months after the addition of L-carnitine supplementation, there was a significant increase in haemoglobin level, while there were significant de- 
TABLE 1. Comparison between studied groups regarding demographic data

\begin{tabular}{|c|c|c|c|c|c|c|}
\hline Parameter & \multicolumn{2}{|c|}{$\begin{array}{l}\text { Group } 1 \\
(n=15)\end{array}$} & \multicolumn{2}{|c|}{$\begin{array}{l}\text { Group } 2 \\
(n=15)\end{array}$} & $t$ test & $p$ value \\
\hline \multicolumn{7}{|l|}{ Age } \\
\hline Mean $\pm S D$ & \multicolumn{2}{|c|}{$10.80 \pm 2.73$ years } & \multicolumn{2}{|c|}{$11.00 \pm 3.79$ years } & \multirow[t]{2}{*}{-0.166} & \multirow[t]{2}{*}{$0.870 \mathrm{NS}$} \\
\hline Range & \multicolumn{2}{|c|}{$8-16$ years } & \multicolumn{2}{|c|}{$6-16$ years } & & \\
\hline \multicolumn{7}{|l|}{ Sex } \\
\hline \multicolumn{5}{|l|}{ Female } & \multirow{6}{*}{$\begin{array}{c}X^{2} \\
0.00\end{array}$} & \multirow[t]{6}{*}{$1.00 \mathrm{NS}$} \\
\hline No. & \multicolumn{2}{|c|}{7} & \multicolumn{2}{|c|}{7} & & \\
\hline$\%$ & \multicolumn{2}{|c|}{$46.7 \%$} & \multicolumn{2}{|c|}{$46.7 \%$} & & \\
\hline \multicolumn{5}{|l|}{ Male } & & \\
\hline No. & \multicolumn{2}{|c|}{8} & \multicolumn{2}{|c|}{8} & & \\
\hline$\%$ & \multicolumn{2}{|c|}{$53.3 \%$} & \multicolumn{2}{|c|}{$53.3 \%$} & & \\
\hline \multicolumn{7}{|l|}{ Height } \\
\hline Mean $\pm S D$ & \multicolumn{2}{|c|}{$125.06 \pm 7.61 \mathrm{~cm}$} & \multicolumn{2}{|c|}{$127.33 \pm 11.82 \mathrm{~cm}$} & -0.625 & $0.537 \mathrm{NS}$ \\
\hline Weight & & & & & & \\
\hline Mean $\pm S D$ & & & & & 0.518 & $0.608 \mathrm{NS}$ \\
\hline & No. & $\%$ & No. & $\%$ & $X^{2}$ & $1.00 \mathrm{NS}$ \\
\hline Height centile & & & & & 0.00 & \\
\hline$<3^{\text {rd }}$ & 11 & 73.3 & 11 & 73.3 & & \\
\hline $3^{\text {rd }}-97^{\text {th }}$ & 3 & 20 & 3 & 20 & & \\
\hline$>97^{\text {th }}$ & 1 & 6.6 & 1 & 6.6 & & \\
\hline Weight centile & & & & & & \\
\hline$<3^{\text {rd }}$ & 12 & 80 & 12 & 80 & & \\
\hline $3^{\text {rd }-97^{\text {th }}}$ & 2 & 13.3 & 2 & 13.3 & & \\
\hline$>97^{\text {th }}$ & 1 & 6.6 & 1 & 6.6 & & \\
\hline BMI centile & & & & & & \\
\hline$<5^{\text {th }}$ & 11 & 73.3 & 11 & 73.3 & & \\
\hline $5^{\text {th }}-97^{\text {th }}$ & 3 & 20 & 3 & 20 & & \\
\hline$>97^{\text {th }}$ & 1 & 6.6 & 1 & 6.6 & & \\
\hline & No. & $\%$ & No. & $\%$ & $x^{2}$ & $1.00 \mathrm{NS}$ \\
\hline SBP centile & & & & & 0.00 & \\
\hline$<95^{\text {th }}$ & 5 & 33.3 & 5 & 33.3 & & \\
\hline$>95^{\text {th }}$ & 10 & 66.6 & 10 & 66.6 & & \\
\hline DBP centile & & & & & & \\
\hline$<95^{\text {th }}$ & 6 & 40 & 6 & 40 & & \\
\hline$>95^{\text {th }}$ & 9 & 60 & 9 & 60 & & \\
\hline $\mathrm{SBP} \mathrm{mmHg}$ & & & & & & \\
\hline Mean $\pm S D$ & & & & & -0.078 & 0.939 NS \\
\hline $\mathrm{DBP} \mathrm{mmHg}$ & & & & & & \\
\hline Mean $\pm S D$ & & & & & 0.676 & $0.505 \mathrm{NS}$ \\
\hline
\end{tabular}

creases in mean ESA dose and ERI in group I treated with L-carnitine and erythropoietin compared to Group II treated with erythropoietin only, in paediatric patients on regular haemodialysis.

\section{DISCUSSION}

Renal anaemia is a common complication of chronic kidney disease (CKD). The decline of renal function 
TABLE 2. Comparison between studied groups regarding laboratory investigations

\begin{tabular}{|c|c|c|c|c|c|}
\hline \multicolumn{2}{|l|}{ Parameter } & \multirow{2}{*}{$\begin{array}{c}\begin{array}{c}\text { Group } 1 \\
(n=15)\end{array} \\
59.58 \pm 17.69 \\
\end{array}$} & \multirow{2}{*}{$\begin{array}{c}\begin{array}{c}\text { Group } 2 \\
(n=15)\end{array} \\
55.33 \pm 26.89\end{array}$} & \multirow{2}{*}{$\begin{array}{l}t \text { test } \\
0.511 \\
\end{array}$} & \multirow{2}{*}{$\begin{array}{l}p \text { value } \\
0.614 \text { NS } \\
\end{array}$} \\
\hline S. urea pre dialysis (mg/dl) & Mean \pm SD & & & & \\
\hline S. creatinine pre dialysis $(\mathrm{mg} / \mathrm{dl})$ & Mean $\pm S D$ & $6.53 \pm 1.99$ & $6.33 \pm 1.65$ & 0.305 & $0.763 \mathrm{NS}$ \\
\hline S. urea post dialysis (mg/dl) & Mean $\pm S D$ & $21.26 \pm 11.89$ & $20.60 \pm 18.77$ & 0.116 & 0.908 NS \\
\hline S. creatinine post dialysis (mg/dl) & Mean $\pm S D$ & $2.62 \pm 1.04$ & $2.47 \pm 0.73$ & 0.446 & 0.659 NS \\
\hline Urea reduction ratio (URR)\% & Mean $\pm S D$ & $64.89 \pm 5.98$ & $67.69 \pm 7.91$ & 1.87 & $0.078 \mathrm{NS}$ \\
\hline Calcium (Ca) (mg/dl) & Mean \pm SD & $7.99 \pm 1.84$ & $8.55 \pm 0.80$ & $-1.067-$ & $0.295 \mathrm{NS}$ \\
\hline Phosphorus (P) (mg/dl) & Mean $\pm S D$ & $5.49 \pm 1.66$ & $4.75 \pm 2.21$ & 1.045 & $0.305 \mathrm{NS}$ \\
\hline Parathyroid hormone (PTH) (pg/ml) & Mean \pm SD & $798.47 \pm 440.14$ & $791.27 \pm 487.09$ & 0.042 & $0.966 \mathrm{NS}$ \\
\hline Serum iron $(\mu \mathrm{g} / \mathrm{dl})$ & Mean \pm SD & $74.00 \pm 35.00$ & $69.67 \pm 25.38$ & 0.388 & $0.701 \mathrm{NS}$ \\
\hline $\mathrm{TIBC}(\mu \mathrm{g} / \mathrm{dl})$ & Mean \pm SD & $222.73 \pm 62.64$ & $239.93 \pm 59.84$ & -0.769 & $0.448 \mathrm{NS}$ \\
\hline Ferritin (ng/ml) & Mean $\pm S D$ & $782.73 \pm 589.51$ & $897.80 \pm 631.92$ & -0.516 & $0.610 \mathrm{NS}$ \\
\hline Transferrin (\%) & Mean $\pm S D$ & $80.97 \pm 117.72$ & $30.20 \pm 8.23$ & 1.666 & 0.107 NS \\
\hline
\end{tabular}

$S$ - significant difference ( $p \leq 0.05)$; NS - no significant difference $(p>0.05)$; TIBC - total iron binding capacity

TABLE 3. Comparison between studied groups regarding haemoglobin level, erythropoietin-stimulating agent dose, and erythropoietinresistance index

\begin{tabular}{|l|l|l|c|c|c|c|}
\hline \multicolumn{2}{|c|}{} & $\begin{array}{c}\text { Group 1 } \\
(\boldsymbol{n}=15)\end{array}$ & $\begin{array}{c}\text { Group 2 } \\
(\boldsymbol{n}=15)\end{array}$ & t test & $p$ value \\
\hline \multirow{2}{*}{ HB } & \multirow{2}{*}{ MEAN \pm SD } & BEFORE START of L-carnitine treatment & $10.97 \pm 1.39 \mathrm{mg} / \mathrm{dl}$ & $10.73 \pm 1.53 \mathrm{mg} / \mathrm{dl}$ & 0.440 & $0.663 \mathrm{NS}$ \\
\cline { 3 - 7 } & & AFTER 6 months of L-carnitine treatment & $11.98 \pm 1.07 \mathrm{mg} / \mathrm{dl}$ & $10.85 \pm 1.48 \mathrm{mg} / \mathrm{dl}$ & 0.18 & $0.02 \mathrm{~S}$ \\
\hline \multirow{2}{*}{ ESA } & \multirow{2}{*}{ MEAN \pm SD } & BEFORE START of L-carnitine treatment & $149.11 \pm 43.98 \mathrm{IU} / \mathrm{kg}$ & $149.11 \pm 43.98 \mathrm{IU} / \mathrm{kg}$ & 0.000 & $1.000 \mathrm{NS}$ \\
\cline { 3 - 7 } & & AFTER 6 months of L-carnitine treatment & $95.12 \pm 10.99 \mathrm{IU} / \mathrm{kg}$ & $149.11 \pm 43.98 \mathrm{IU} / \mathrm{kg}$ & -14.00 & $0.00 \mathrm{~S}$ \\
\hline ERI & MEAN \pm SD & AFTER 6 months of L-carnitine treatment & $229.59 \pm 21.95 \mathrm{IU} / \mathrm{kg} / \mathrm{g}$ & $360.15 \pm 71.105 \mathrm{IU} / \mathrm{kg} / \mathrm{g}$ & -9.09 & $0.00 \mathrm{~S}$ \\
\hline
\end{tabular}

$S$ - significant difference $(p \leq 0.05)$; NS - no significant difference $(p>0.05)$; ERI - erythropoietin resistance index

is associated with an increased incidence and severity of anaemia, and it affects more than $90 \%$ of patients with end-stage renal disease [20].

It not only affects the quality of life but also causes adverse cardiovascular events that can increase mortality $[21,22]$.

Deficiency of erythropoietin and iron are the main causes of anaemia in patients on regular haemodialysis [23]. The introduction of erythropoietin-stimulating agents dramatically improves renal anaemia. However, some patients do not respond effectively to these agents, which is known as erythropoietin (EPO) hyporesponsiveness or resistance [24].

Responsiveness to erythropoietin is affected by many factors such as serum albumin level, secondary hyperparathyroidism, inflammatory response, and iron deficiency [25]. There was a marked reduction in RBC survival in patients undergoing intermittent haemodialysis compared with healthy controls [26].

There are several actions of LC on circulating RBC suggesting that LC and carnitine palmitoyl transferase play a role in membrane phospholipid fatty acid turnover and may improve the viscoelastic properties of RBC by intervening on both the outer and the inner side of the erythrocyte membrane. Also, their anti-inflammatory activity is suggested to play a role in the prevention of apoptosis [27, 28].

So, we aimed to study the effect of L-carnitine (LC) therapy on anaemia and its treatment with erythropoietin therapy in paediatric patients on regular haemodialysis. We analysed serum levels of haemoglobin and erythrocytes, erythropoiesis-stimulating agent (ESA) dose, and erythropoietin-resistance index (ERI) calculated at baseline and then on follow-up after 6 months.

This study revealed no significant differences between the studied groups. However, we revealed that about $53.3 \%$ of all studied haemodialysis patients were male. This is in agreement with Tanvir et al., [29] who found that haemodialysis patients were more often male.

Regarding anthropometric measurements and the urea reduction ratio in our study, there was no statistically significant difference between the groups regarding demographic data. These results were in agreement with the study of Lotfy et al. [30]. This implies good selection of cases.

The present study showed that L-carnitine (LC) therapy improved anaemia in paediatric patients on regular haemodialysis in group I when compared to group 
II (treated with erythropoietin only). This agrees with Mortazavi et al., [31] who found that haemoglobin levels rose significantly in patients receiving oral L-carnitine $(p=0.04)$ but not in patients receiving placebo $(p>0.05)$. Also, Bellinghieri et al., [32] reported a significant increase in the haematocrit values at the end of a 2 -month treatment with LC at dose of $2 \mathrm{~g}$ /day orally.

Similarly, Steiber et al., [33] found that a carnitine-treated group showed a statistically significant decrease in serum C-reactive protein and increase in blood haemoglobin, serum albumin, transferrin, and body mass index.

Furthermore, the addition of $\mathrm{L}$ carnitine to erythropoietin caused a significant decrease in mean use of ESA in group I treated with both L-carnitine (LC) and erythropoietin for 6 months when compared to group II treated with erythropoietin only. This agrees with Kletzmayr et al., [34] who reported that LC supplementation increased haemoglobin in haemodialysis patients without $\mathrm{rHuEPO}$ therapy and reduced rHuEPO requirements for the treatment of anaemia in haemodialysis patients.

These results agree with Murphy et al., [35] who suggested that L-carnitine would reduce the necessary EPO dose.

Similarly, Labonia [36] found a reduction in the rHuEPO requirement of the active group following LC intravenous administration after every dialysis session for 6 months $(p<0.02)$. Kletzmayr et al. [34] revealed that after 4 months of co-administration of LC and intravenous iron, the requirement of weekly $\mathrm{rHuEPO}$ dose was significantly decreased in haemodialysis patients $(p<0.001)$.

Also, in agreement with our results, Bilal Aoun et al. [37] analysed the effect of intravenous L-carnitine supplementation on the erythropoietin (EPO) requirement in 6 paediatric haemodialysis patients. They found increased $\mathrm{Hb}$ levels and decreased EPO requirement.

In contrast to our results, Sabry et al. [38] revealed no significant improvement in haemoglobin and erythropoietin dose after 6 months of addition of LC therapy to erythropoietin when compared to controls who received erythropoietin alone. This agrees with Vaux et al., [39] who could not demonstrate any beneficial effect of LC on renal anaemia. Also, Lilien et al. [40] found that there was no significant change in rhEPO requirement, haemoglobin level, and haematocrit during the study. They concluded that there was no beneficial effect of supplementation with L-carnitine on rhEPO requirement in children on dialysis.

This heterogeneity of results could be due to the difference in observation periods among these studies.

Kopple [41] found that found that the erythropoietin dose was significantly decreased in patients supplemented with 1 carnitine ( $1 \mathrm{~g}$ /day orally for 4 months, $p=0.001$ ), while they reported no significant increase in $\mathrm{Hb}$ concentrations.
In our study, an improvement of ERI was observed within 6 months after carnitine administration. This is in agreement with a study conducted by Savica et al., [42] who found that carnitine supplementation enhanced the response to the administered dose of erythropoietin in these patients, which ended in increased haemoglobin, reduced dose of required erythropoietin, and decreased index of erythropoietin resistance. This reduction of ERI strongly suggests that 1 carnitine supplementation might expand the erythrocyte lifespan.

The KDIGO guideline suggests not using adjuvants to an ESA such as vitamin C, vitamin D, vitamin E, folic acid, LC, or pentoxifylline because their evidence level was not sufficient [43]. The current study revealed that ESA and ERI had a statistically significant decrease after 3 months among Group 1 (receiving L-carnitine [LC] and erythropoietin therapy) but not among Group 2 (receiving erythropoietin therapy only).

\section{CONCLUSIONS}

L-carnitine may be used as an adjuvant therapy in paediatric haemodialysis patients to decrease the dosage of erythropoietin-simulating agents (ESA) and the erythropoietin-resistance index (ERI) while maintaining adequate levels of serum haemoglobin.

Limitations of the study: the sample size was small; prospective multi-centre studies on larger numbers of patients are recommended.

\section{DISCLOSURE}

The authors declare no conflict of interest.

\section{REFERENCES}

1. Fishbane S, Spinowitz B. Update on anemia in ESRD and earlier stages of CKD: core curriculum 2018. Am J Kidney Dis 2018; 71: 423-435.

2. Hazin MAA. Anemia in chronic kidney disease. Rev Assoc Med Bras 2020; 66 (Suppl 1): s55-s58.

3. Kurella Tamura M, Vittinghoff E, Yang J. Anemia and risk for cognitive decline in chronic kidney disease. BMC Nephrol 2016; 17: 13.

4. KDIGO (Kidney Disease Improving Global Outcomes). CKD work group. Clinical practice guideline for the evaluation and management of chronic kidney disease. Kidney Int Suppl 2013; 3: 1-150.

5. Luo J, Jensen DE, Maroni BJ, et al. Spectrum and burden of erythropoiesis-stimulating agent hyporesponsiveness among contemporary hemodialysis patients. Am J Kidney Dis 2016; 68: 763-771.

6. Santos EJF, Hortegal EV, Serra HO, et al. Epoetin alfa resistance in hemodialysis patients with chronic kidney disease: a longitudinal study. Braz J Med Biol Res 2018; 51: e7288.

7. Gillespie IA, Macdougall IC, Richards S, et al. Factors precipitating erythropoiesis-stimulating agent responsiveness in a European haemodialysis cohort: case-crossover study. Pharmacoepidemiol Drug Saf 2015; 24: 414-426.

8. Golper TA, Goral S, Becker BN. CB L-carnitine treatment of anemia. Am J Kidney Dis 2003; 41: 27-34. 
9. Yilmaz MI, Solak Y, Covic A. Renal anemia of infammation: the name is self-explanatory. Blood Purif 2011; 32: 220-225.

10. Kanbay M, Perazella MA, Kasapoglu B. Erythropoiesis stimulatory agent- resistant anemia in dialysis patients: review of causes and management. Blood Purif 2010; 29: 1-12.

11. Mercadal L, Coudert M, Vassault A, et al. L-carnitine treatment in incident hemodialysis patients: the multicenter, randomized, double-blinded, placebo-controlled CARNIDIAL trial. Clin J Am Soc Nephrol 2012; 7: 1836-1842.

12. Bonomini M, Zammit V, Pusey CD, et al. Pharmacological use of L-carnitine in uremic anemia: has its full potential been exploited? Pharmacol Res 2011; 63: 157-164.

13. Kalantar-Zadeh K, Block G, McAllister CJ, et al. Appetite and inflammation, nutrition, anemia, and clinical outcome in hemodialysis patients. Am J Clin Nutr 2004; 80: 299-307.

14. Warady BA, Borum P, Stall C, et al. Carnitine status of pediatric patients on continuous ambulatory peritoneal dialysis. Am J Nephrol 1990; 10: 109-114.

15. Gagnadoux MF, Loirat C, Berthélémé JP, et al. Treatment of anemia in hemodialyzed children using recombinant human erythropoietin (Eprex). Results of a French multicenter clinical trial. Nephrologie 1994; 15: 207-211.

16. Jindal KK, Manuel A, Goldstein MB. Percent reduction in blood urea concentration during hemodialysis (PRU): a simple and accurate method to estimate Kt/V urea. ASAIO Trans 1987; 33: 286-288.

17. Basile C, Casino F, Lopez T. Percent reduction in blood urea concentration during dialysis estimates $\mathrm{Kt} / \mathrm{V}$ in a simple and accurate way. Am J Kidney Dis 1990; 15: 40-45.

18. Lowrie EG, Lew NL. The urea reduction ratio (URR) a simple method for evaluating hemodialysis treatment. Contemp Dial Nephrol 1991; 12: 11-20.

19. Okazaki M, Komatsu M, Kawaguchi H, et al. Erythropoietin resistance index and the all-cause mortality of chronic hemodialysis patients. Blood Purification 2014; 37: 106-112.

20. Li Y, Shi H, Wang WM, et al. Prevalence, awareness, and treatment of anemia in Chinese patients with nondialysis chronic kidney disease: first multicenter, cross-sectional study. Medicine (Baltimore) 2016; 95: e3872.

21. Suzuki M, Hada Y, Akaishi M, et al. Effects of anemia correction by erythropoiesis-stimulating agents on cardiovascular function in non-dialysis patients with chronic kidney disease. Int Heart J 2012; 53: 238-243.

22. Hauber B, Caloyeras J, Posner J, et al. Hemodialysis patients' preferences for the management of anemia. BMC Nephrology 2017; 18: 253.

23. Mikhail A, Brown C, Williams JA, et al. Renal association clinical practice guideline on anaemia of chronic kidney disease. BMC Nephrology 2017; 18: 345.

24. Kim IY, Kim JH, Kim MJ, et al. Low 1,25-dihydroxyvitamin D level is associated with erythropoietin deficiency and endogenous erythropoietin resistance in patients with chronic kidney disease. Int Urol Nephrol 2018; 50: 2255-2260.

25. Ogawa T, Nitta T. Erythropoiesis-stimulating agent hyporesponsiveness in end-stage renal disease patients. Contrib Nephrol 2015; 185: 76-86.

26. Arduini A, Bonomini M, Clutterbuck EJ, Laffan MA, Pusey CD. Effects of L-carnitine administration on erythrocyte survival in hemodialysis patients. Nephrol Dial Transplant. 2006; 21:2671-2672.

27. Fortin G, Yurchenko K, Collette C, et al. L-Carnitine, a diet component and organic cation transporter OCTN ligand, displays immune suppressive properties and abrogates intestinal inflammation. Clin Exp Immunol 2009; 156: 161-171.

28. Ly J, Marticorena R, Donnelly S. Red blood cell survival in chronic renal failure. Am J Kidney Dis 2004; 44: 715-719.
29. Tanvir S, Butt G-D, Taj R. Prevalence of Depression and Anxiety in Chronic Kidney Disease Patients on Haemodialysis. Ann Pak Inst Med Sci 2013; 9: 64-67

30. Lotfy HM, Sabry SM, Ghobrial EE, et al. The effect of regular hemodialysis on the nutritional status of children with end-stage renal disease. Saudi Journal of Kidney Diseases and Transplantation 2015; 26: 263.

31. Mortazavi M, Seirafian S, Eshaghian A, et al. Associations of oral L-carnitine with hemoglobin, lipid profile, and albumin in hemodialysis patients. J Res Med Sci 2012; 17: 33-37.

32. Bellinghieri G, Savica V, Mallamace A, et al. Correlation between increased serum and tissue L -carnitine levels and improved muscle symptoms in hemodialyzed patients. Am J Clin Nutr 1983; 38: 523531.

33. Steiber AL, Davis AT, Spry L, et al. Carnitine treatment improved quality-of-life measure in a sample of Midwestern hemodialysis patients. JPEN J Parenter Enteral Nutr 2006; 30: 10-15.

34. Kletzmayr J, Mayer G, Legenstein E. Anemia and carnitine supplementation in hemodialyzed patients. Kidney Int 1999; 55: S93-S106.

35. Murphy WJA, Steiber A, Connery GC, et al. Altered carnitine metabolism in dialysis patients with reduced physical function may be due to dysfunctional fatty acid oxidation. Nephrol Dial Transplant 2012; $27: 304-310$

36. Labonia WD. L-Carnitine effects on anemia in hemodialyzed patients treated with erythropoietin. Am J Kidney Dis 1995; 26: 757764.

37. Bilal A, Etienne B, Renata V, et al. L-carnitine supplementation and EPO requirement in children on chronic hemodialysis. Pediatric Nephrology 2010; 25: 557-560.

38. Sabry AA. The role of oral L-Carnitine therapy in chronic hemodialysis patients. Saudi J Kidney Dis Transpl 2010; 21: 454-459.

39. Vaux E, Taylor DJ, Altman P, et al., Effect of carnitine supplementation on muscle metabolism by the use of magnetic resonance spectroscopy and near-infrared spectroscopy in end-stage renal disease. Nephron Clin Pract 2004; 97: 41-48.

40. Lilien MR, Duran M, Quak JM, et al. Oral L-carnitine does not decrease erythropoietin requirement in pediatric dialysis. Pediatr Nephrol 2000; 15: 17-20.

41. Kopple JD. National kidney foundation K/DOQI clinical practice guidelines for nutrition in chronic renal failure. Am J Kidney Dis 2001; 37: S66-70.

42. Savica V, Santoro D, Mazzaglia G. L-carnitine Infusions May Suppress Serum C-Reactive Protein and Improve Nutritional Status in Maintenance Hemodialysis Patients. J Ren Nutr 2005; 15: 225-230.

43. Kidney disease: Improving Global Outcomes (KDIGO):Anemia Work Group. KDIGO clinical practice guideline for anemia in chronic kidney disease August 2012 Kidney International Supplements 2: 279-335. 